\title{
Reducing Preconception Risks Among African American Women with Conversational Agent Technology
}

\author{
Brian Jack, MD, Timothy Bickmore, PhD, Megan Hempstead, MPH, \\ Leanne Yinusa-Nyabkoon, ScD, OTR/L, Ekaterina Sadikova, MPH, \\ Suzanne Mitchell, MD, MSc, Paula Gardiner, MD, MPH, Fatima Adigun, BS, \\ Brian Penti, MD, Daniel Schulman, PhD, and Karla Damus, PhD, MSPH, RN
}

Background: Systems and tools are needed to identify and mitigate preconception health (PCH) risks, particularly for African American (AA) women, given persistent health disparities. We developed and tested "Gabby," an online preconception conversational agent system.

Methods: One hundred nongravid AA women 18-34 years of age were screened for over 100 PCH risks and randomized to the Gabby or control group. The Gabby group interacted with the system for up to six months; the control group received a letter indicating their health risks with a recommendation to talk with their clinician. The numbers, proportions, and types of risks were compared between groups.

Results: There were 23.7 (SD 5.9) risks identified per participant. Eighty-five percent (77 of 91) provided 6 month follow up data. The Gabby group had greater reductions in the number (8.3 vs. 5.5 risks, $P<.05)$ and the proportion $(27.8 \%$ vs $20.5 \%, P<0.01)$ of risks compared to controls. The Gabby group averaged 63.7 minutes of interaction time. Seventy-eight percent reported that it "was easy to talk to Gabby" and 64\% used information from Gabby to improve their health.

Conclusion: Gabby was significantly associated with preconception risk reduction. More research is needed to determine if Gabby can benefit higher risk populations and if risk reduction is clinically significant. (J Am Board Fam Med 2015;28:441-451.)

Keywords: Health Care Disparities, Health Information Technology, Health Promotion, Preconception Care, Reproductive Health

Despite mounting scientific evidence that enhancing a woman's health before pregnancy improves perinatal outcomes for her and her infant,

This article was externally peer reviewed.

Submitted 21 November 2014; revised 25 February 2015; accepted 27 February 2015.

From the Department of Family Medicine, Boston University School of Medicine/Boston Medical Center, Boston, MA (BJ, MH, ES, SM, PG, FA, BP, KD); the College of Computer and Information Science, Northeastern University, Boston, MA (TB); Department of Occupational Therapy, Sargent College of Health and Rehabilitation Sciences, Boston University, Boston, MA (LY-N); and the Veteran's Administration, Boston Healthcare System, Jamaica Plain, MA (DS).

Funding: This project was supported by the Health Resources and Services Administration (HRSA) of the US Department of Health and Human Services (HHS) under grant no. R40 MC21510 (BJ); the National Institute on Minority Health and Health Disparities grant no. R01 MD006213 many women enter pregnancy in poor health and at risk for preventable adverse pregnancy outcomes. In addition, about half of pregnancies are unplanned, making it important to promote preconception health $(\mathrm{PCH})$ and deliver preconception

(BJ); Agency for Healthcare Research and Quality contract no. HHSA290200600012I (BJ); and the W. K. Kellogg Foundation grant no. P3024018 (BJ).

Conflict of interest: The authors are responsible for the production of Gabby, the preconception conversational agent, and retain the intellectual property rights.

Disclaimer: This information or content and conclusions are those of the author and should not be construed as the official position or policy of, nor should any endorsements be inferred by the Health Resources and Services Administration, the US Department of Health and Human Services, or the US government.

Corresponding author: Brian Jack, MD, Department of Family Medicine, Dowling 5, Boston Medical Center, 1 BMC Place, Boston, MA 02118 (E-mail: brian.jack@bmc.org). 
care (PCC) to all women of reproductive age, regardless of pregnancy intention. ${ }^{1}$ The Centers for Disease Control and Prevention (CDC) defines PCC as "interventions that aim to identify and modify biomedical, behavioral, and social risks to a woman's health or pregnancy outcome through prevention and management by emphasizing those factors that must be acted on before conception or early in pregnancy to have maximal impact." ${ }^{2} \mathrm{PCH}$ and PCC involve addressing a range of issues, such as family planning, specific medical conditions (eg, diabetes), exposure to teratogens, substance abuse, and preventive interventions (eg, immunization and folic acid supplementation). ${ }^{3}$

In 2008 the CDC Select Panel on Preconception Care clinical workgroup outlined those content areas that are important to identify and address to improve maternal and infant outcomes ${ }^{4}$; the workgroup identified implementation strategies as a top priority. ${ }^{5}$ In 2013 , the 2006 CDC preconception goals were updated to include improving the knowledge, attitudes, and behaviors of men and women related to PCC; eliminating disparities in adverse maternal, fetal, and infant outcomes; and ensuring that all US women of childbearing age receive PCC services. ${ }^{6}$ Progress toward the Healthy People 2020 goal to eliminate disparities requires that rates of adverse health outcomes fall more rapidly for African American (AA) women, which is why the Gabby system was designed for this group.

Health information technology presents opportunities to develop innovative tools that assist clinicians in delivering $\mathrm{PCC}^{7}$ and to engage and empower women to improve their PCH. Among the most encouraging advances is the conversational agent, a computerized, animated character that integrates best practices from provider-patient communication theory. They emulate the face-to-face conversational behavior of an empathic clinician, including nonverbal communicative behavior such as gaze, posture, and hand gestures, to deliver tailored education, assess comprehension, and record progress. ${ }^{8-10}$ Conversational agents are a logical option to deliver $\mathrm{PCH}$ information because they can reach a large audience while providing high user acceptability through culturally appropriate content and information appropriate to those with low health literacy. ${ }^{11,12}$ AA women may benefit from conversational agents because of disparities in health literacy levels; according to a 2006 report by the US Department of Education, 58\% of AA adults possess below basic or basic health literacy compared with $28 \%$ of white adults. ${ }^{13}$ There is also evidence that clinicians are more verbally dominant and less patient-centered with AA patients, ${ }^{14}$ and that these systems can overcome clinician time constraints ${ }^{15}$ and assist in delivering recommended preventive care. ${ }^{16}$ Conversational agents also have been used in studies showing significant impact on clinical outcomes. ${ }^{11,17,18}$

Given the success of our previous conversational agent work among inner-city patients, our research team spent 5 years developing and testing the conversational agent "Gabby," who is designed to be used by women to improve their PCH and seek PCC (Figure 1). Gabby can identify women's individual health risks and assess their readiness for behavior change; provide information about each risk; and deliver longitudinal behavior change content to promote the adoption of healthy behaviors and risk resolution. The system helps women create a "My Health To-Do List (MHTDL)," a personal tool that can be updated throughout the intervention to track progress.

Our earlier testing of Gabby demonstrated that the system had the potential to help AA women address preconception risks over a 2-month period. ${ }^{19}$ In this article we report on an enhanced version with more sophisticated elements, including tracking stages of behavioral change, which we tested in a 6-month randomized controlled trial (RCT) of nongravid AA women, most in college, to determine how well Gabby works and to identify additional areas for improvement. The ultimate goal is to produce an effective Gabby system for use either solely by women and/or integrated into care targeting high-risk AA women with lower education and health literacy.

\section{Methods}

We conducted a RCT from March 2013 to February 2014 to determine whether interacting with Gabby could reduce the proportions, numbers, and types of PCH/PCC risks compared with a control group without access to Gabby. The study was approved by the Boston University Medical Center Institutional Review Board.

\section{Design and Implementation}

New dialog scripts and supporting media were developed for this version of Gabby, including: 
Figure 1. An image of "Gabby," the preconception care conversational agent.

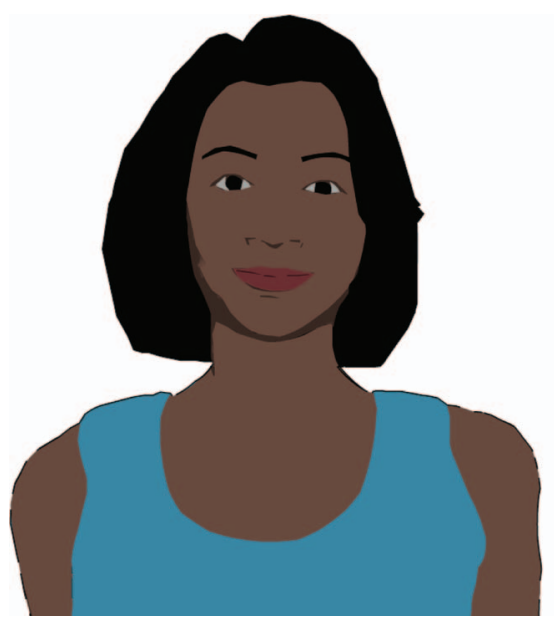

Sounds good!

Let's get started

Okay

Sorry, I didn't hear that.
(1) motivational interviewing dialog for those who were "precontemplative" for a specific risk; (2) dialog to simulate shared decision-making interactions with clinicians; and (3) additional longitudinal interaction using techniques such as goal setting, problem solving, tips, and homework.

\section{Sample}

A purposeful convenience sample of 100 women who self-identified as AA or black, were 18 to 34 years of age, had access to a telephone and computer with Internet, spoke English, and self-reported as not currently pregnant were enrolled from 20 states and the District of Columbia. Participants were recruited through the US Department of Health and Human Services Office of Minority Health's national Preconception Peer Educator (PPE) $\operatorname{program}^{20}(\mathrm{n}=86)$, a Healthy Start site in Florida $(\mathrm{n}=8)$, a Health Expo in Boston $(n=4)$, and word of mouth $(n=2)$. Recruitment materials included E-mails, flyers, and referrals.

\section{Baseline Data}

After providing verbal informed consent by telephone, we collected contact information, demographic data, and administered the General Self Efficacy Scale, ${ }^{21}$ Multidimensional Scale of Perceived Social Support, ${ }^{22}$ Everyday Discrimination Scale, ${ }^{23}$ and the 66-word Rapid Estimate of Adult Literacy in Medicine. ${ }^{24}$

\section{Randomization and Risk Assessment}

Participants were randomized into the Gabby or control groups using sequentially numbered, opaque, sealed envelopes containing the random group assignment. All subjects received an E-mail with the required system log-in information and were asked to complete the risk assessment, which included 107 distinct PCH risk factors classified among 12 content areas. A full description of the content areas and risks has been published ${ }^{4}$; they are listed in Table 1 and outlined in online Appendices 1 and 2. All women received a reminder E-mail with a link to the risk assessment 1 week after enrollment, then biweekly reminders until they completed the risk assessment.

\section{Gabby Group}

Women in the Gabby group received biweekly reminder E-mails with a link. Each interaction consisted of (1) a greeting from Gabby; (2) a review of identified health risks ("My Survey Results"); (3) discussion of risks as selected by the woman (including educational content and behavior change counseling); and (4) a review and update of the My Health To-Do List, which lists the previously discussed risks and self-reported progress (Figure 2).

\section{Control Group}

Each control participant received a letter in the mail containing her list of $\mathrm{PCH}$ risks, with the suggestion to discuss her list with a health care provider. 


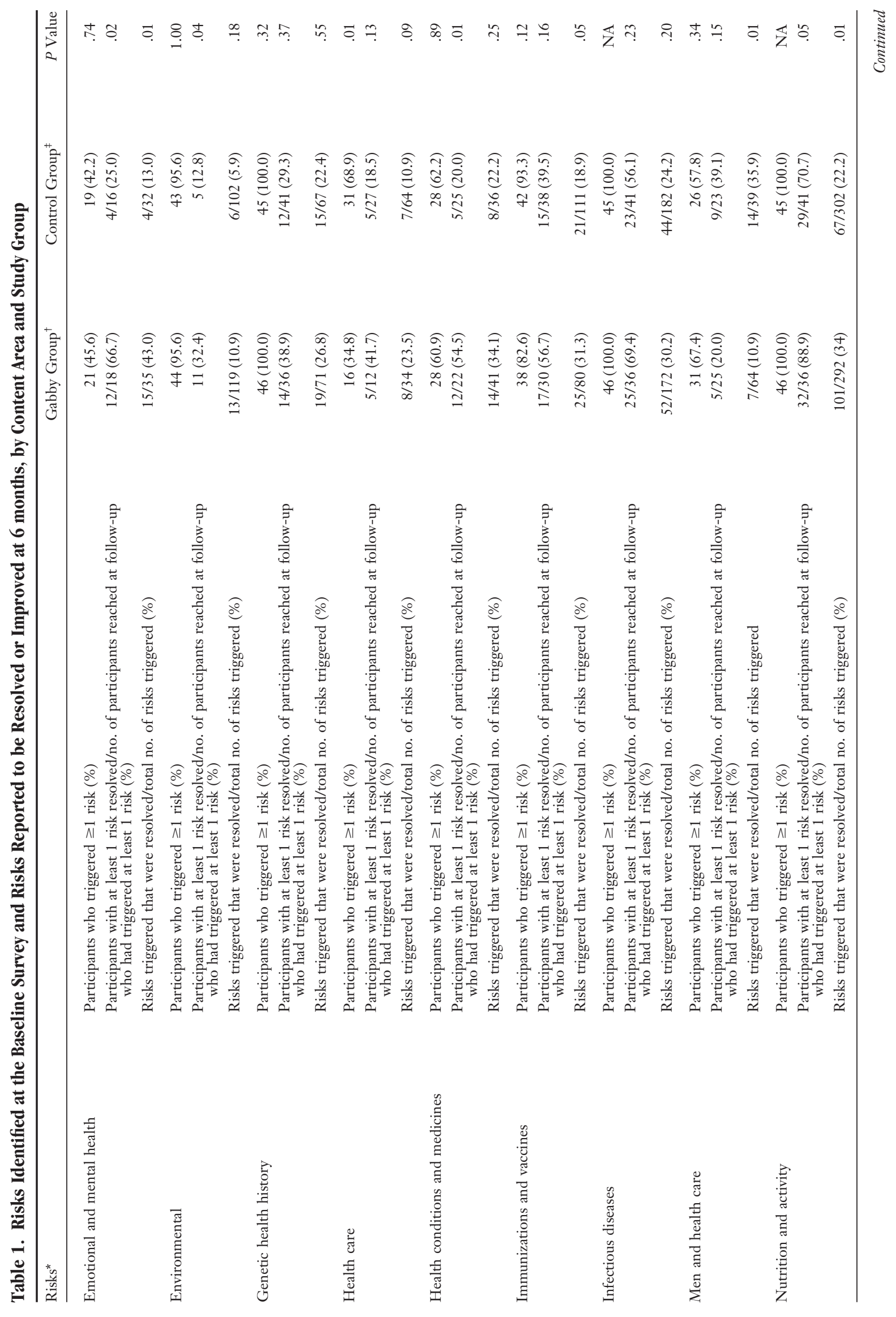



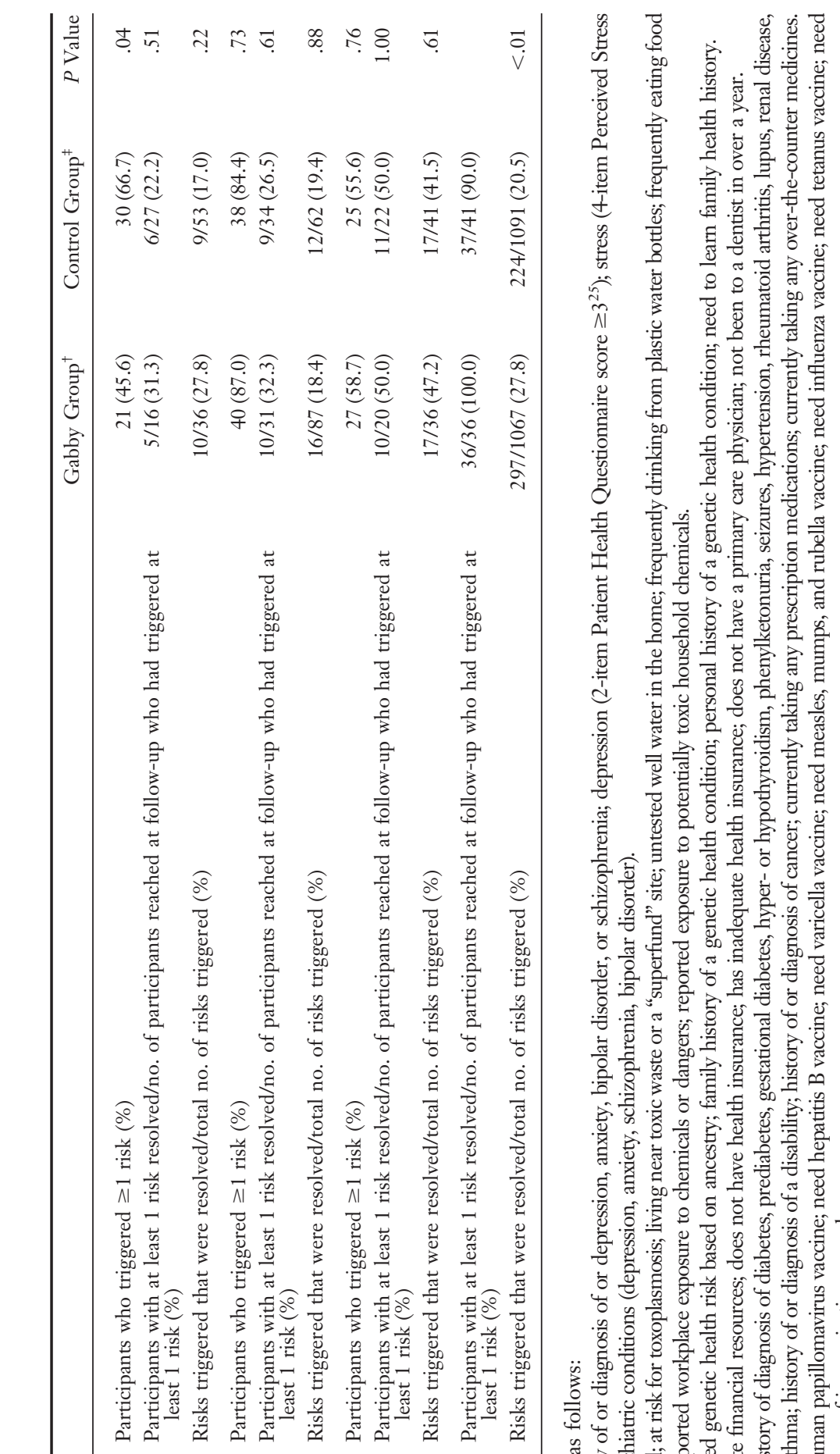

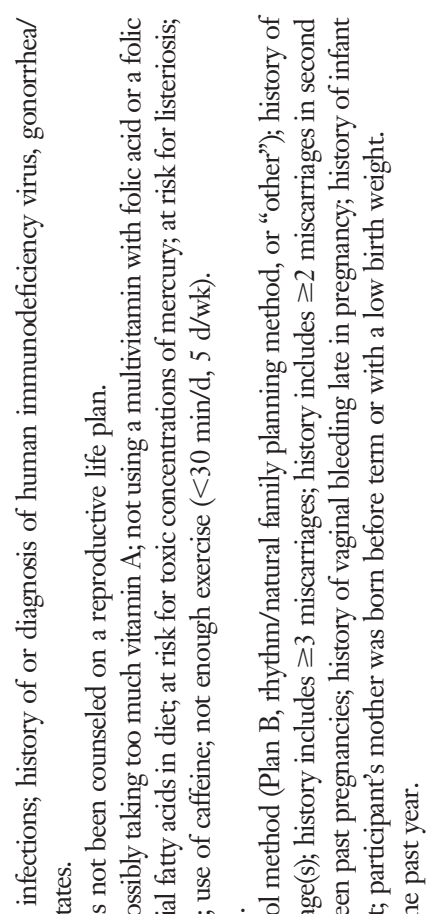

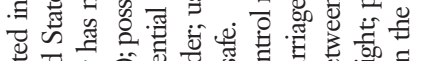

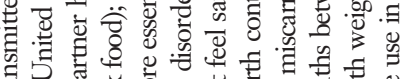

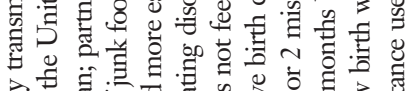

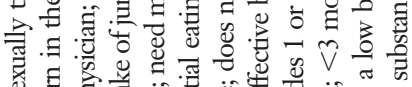

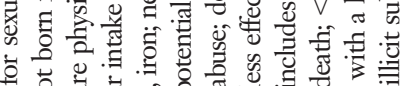

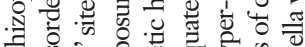

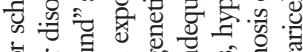

ธ。

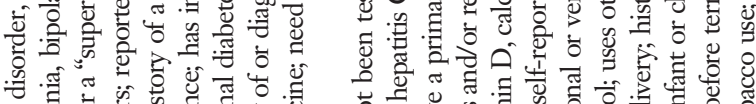

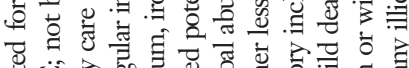

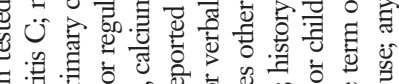

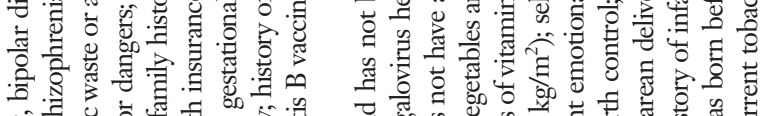

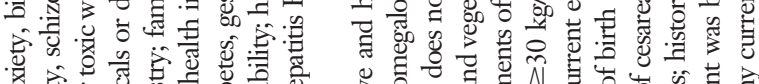

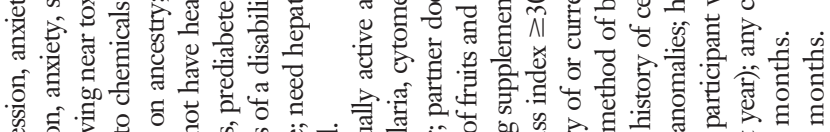

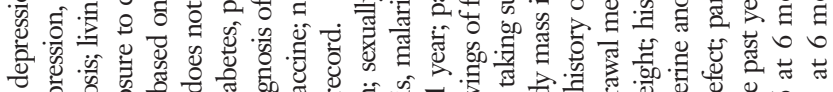

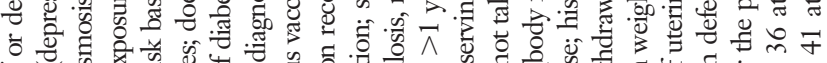

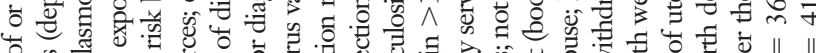

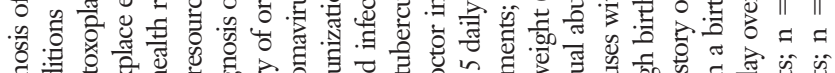

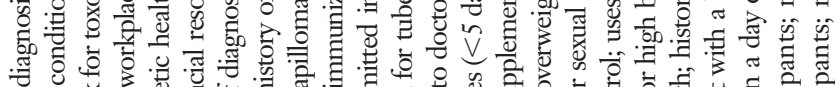

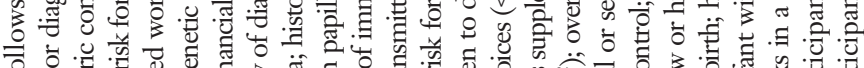

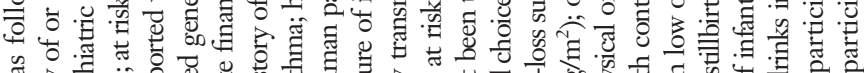

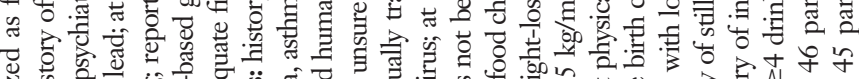
․ㅗㅂ

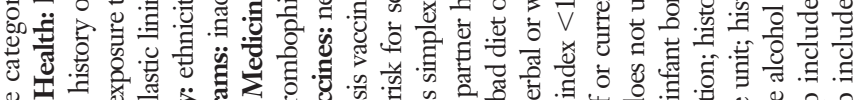
ơ

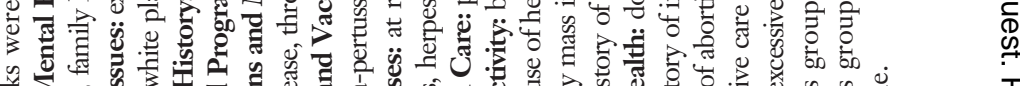

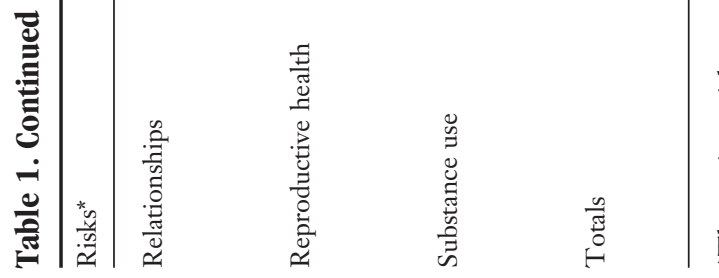

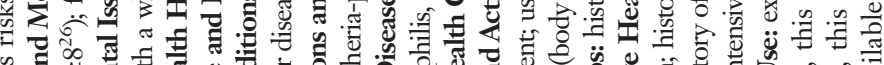

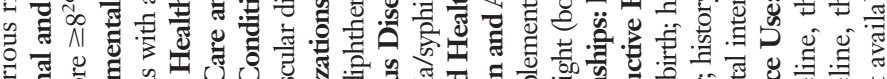

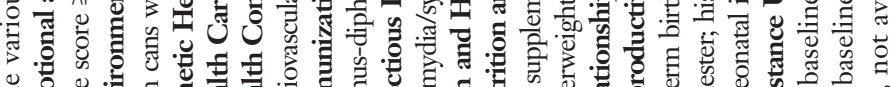

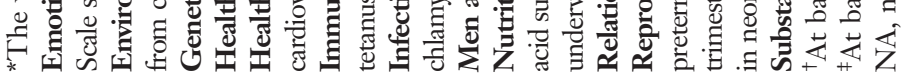


Figure 2. Diagram of a typical Gabby System interaction.

\section{Gabby Version 2}

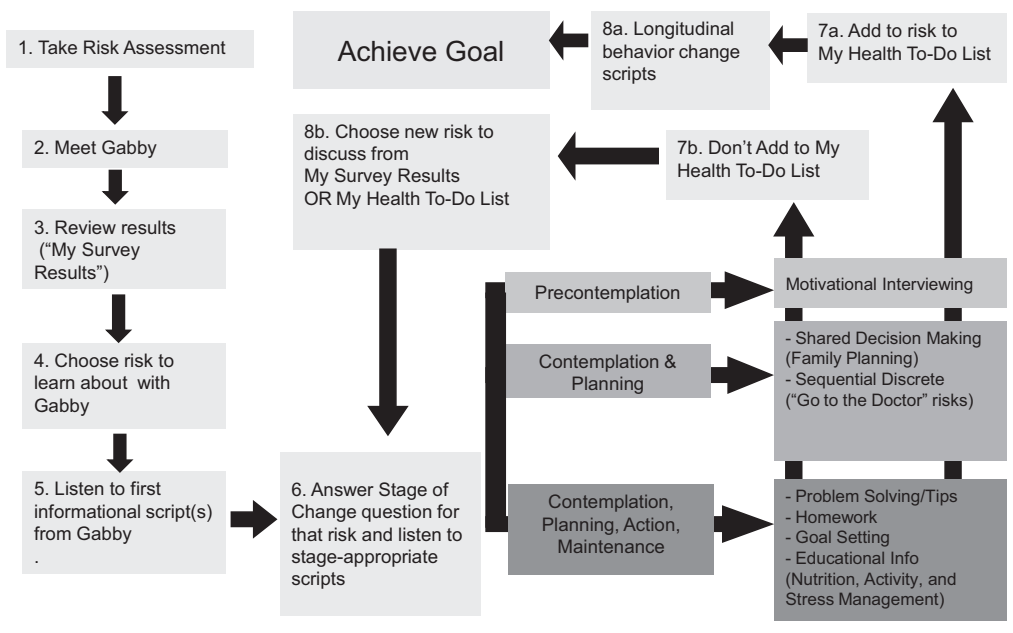

\section{Outcome Data}

Six-month outcome data were collected from all women using an online survey followed by telephone call. Questions not completed online were asked during the telephone call. Information was obtained about each baseline PCH risk to determine whether it was still "active" or "resolved."

Additional outcome data collection included assessment of health care usage during the study period, questions about pregnancy status and outcome, system satisfaction (Gabby group), and risk letter satisfaction (control group). Number and duration of logins were documented within the system. Participants received a \$15 iTunes gift card after completing the outcome phone call.

\section{Statistical Analysis}

Baseline demographic, clinical, and information technology usage characteristics were compared using 2-sided $t$ tests for continuous variables and $\chi^{2}$ tests or Fisher exact tests for categorical and dichotomous variables. Within each $\mathrm{PCH}$ content area, we compared the proportion of the Gabby and control participants who triggered at least 1 risk, the aggregate number of risks triggered (applying the $z$ test for proportions), and the triggered risk rate using the aggregate number of risks triggered divided by the number of participants completing the risk assessment.

To assess the impact of Gabby, we first compared, using a 2 -sample $t$ test, the average number of risks resolved between the Gabby and control groups among participants who completed the risk assessment and the outcome interview. We then compared the proportion of participants who resolved at least 1 of the risks in each content area with those who triggered at least 1 risk at baseline $\left(\chi^{2} /\right.$ Fisher exact tests). The aggregate numbers of risks resolved were calculated by dividing the number of risks resolved by the number triggered at baseline ( $z$ tests for proportions). Finally, we looked at rates of risks resolved within the content areas by study group. The rates were calculated by dividing the aggregate number of risks resolved within a content area by the number of participants who triggered at least 1 risk in this domain at baseline and compared between the 2 study groups using crude Poisson regressions.

\section{Results}

A total of 100 women who met all inclusion criteria consented and were randomized into the study. Complete baseline and 6-month outcome data were obtained from 36 women in the Gabby group and 41 in the control group (Figure 3). There was no significant difference in response rates between groups $(P=.34)$.

The demographic, clinical, and information technology characteristics of the 99 women who provided baseline data are presented in Table 2 . The average age was 25.5 years; about two-thirds 
Figure 3. Diagram of subject participation in study phases.

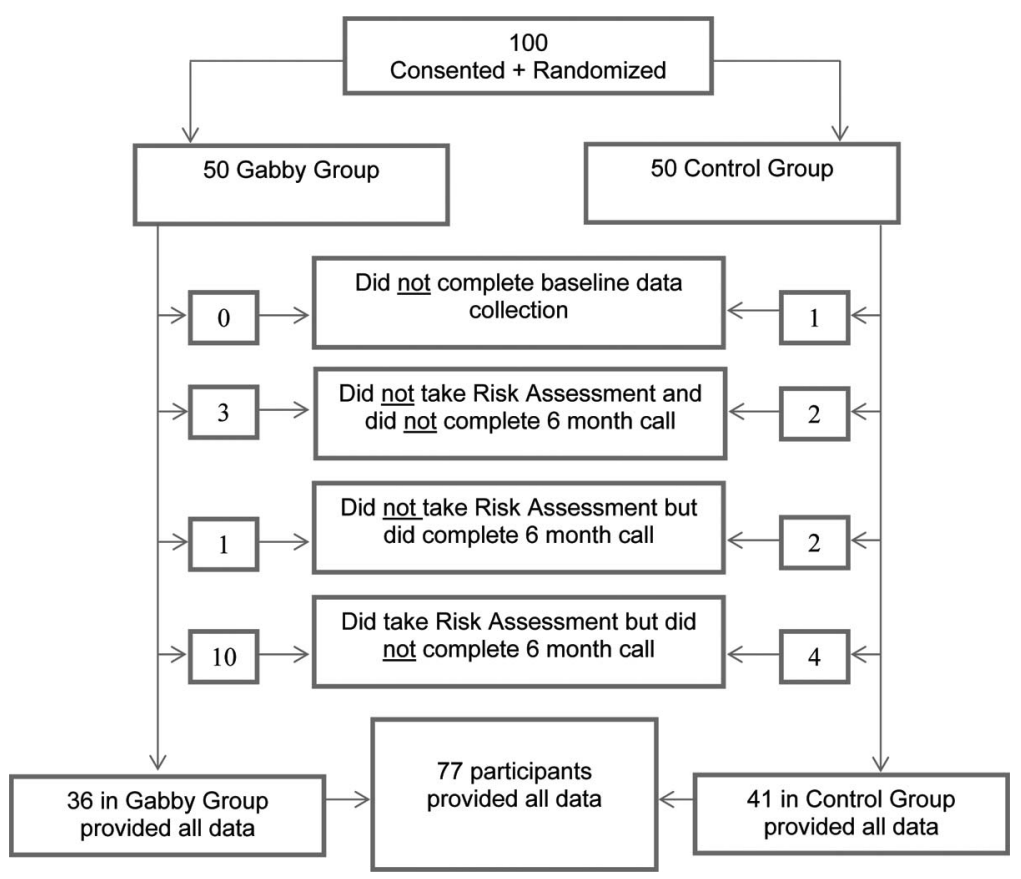

were employed at least part time and completed at least some college, and $41 \%$ were students. Over $90 \%$ read at the high school level or better, and the majority reported high self-efficacy, high social support, and low perceived racial discrimination. More than half had computer access at home, and all used a computer regularly or considered themselves expert. Over $90 \%$ had used computers to access online health information. There were no significant differences in the demographics, clinical characteristics, or information technology literacy and availability between groups.

Table 1 shows the content areas of risks reported at baseline and those risks resolved or improved in 6 months by study group. The average number of risks triggered was 23.7 (standard deviation, 5.9) per participant, 23.2 (6.0) for the Gabby group, and 24.2 (5.8) for the control group. A total of 2158 risks were triggered by the 91 participants who completed the risk assessment (1067 by the Gabby group and 1091 by the control group). The most common content area triggered among all participants was "nutrition and activity" (27.5\%), followed by "infectious disease" (16.4\%), "environmental issues" (10.2\%), and "immunizations and vaccines" (8.8\%). The specific risks within each content area are listed at the bottom of Table 1 and in online appendix 1.
During the 6-month intervention period, 42 women interacted with Gabby at least once. There were a total of 144 interactions totaling 2676 minutes. The average session lasted 18.6 minutes (SD, 12.1 minutes), and the average interaction time with Gabby during the study was 63.7 minutes (SD, 70.4 minutes; range, 2.8-286 minutes) per woman. Of the total time interacting with Gabby, $30 \%$ was spent discussing nutrition and activity, and $10.3 \%$ was spent discussing "reproductive health."

Significant differences in risk resolution were found between the Gabby and control groups. Among the 77 women for whom both baseline data and 6-month outcome data were available, 27.8\% $(297 / 1067)$ of the reported risks were resolved in the Gabby group compared with 20.5\% (224/1091) in the control group $(P<.01$; Table 1). At 6 months, women in the Gabby group resolved, on average, 8.3 risks (from the average 23.2 identified), compared with 5.5 risks (of 24.2 identified) in the control group $(P<.01)$. The risks most often resolved by those in the Gabby group were "bad diet or food choices" (18 resolved), "not using multivitamin with folic acid or folic acid supplement" (16 resolved), "at risk for sexually transmitted infection" (15 resolved), "not taking iron supplement" (13 resolved), "use of caffeine" (12 resolved), and "at risk for tuberculosis" (12 resolved). These 6 
Table 2. Participant Demographics, Clinical Characteristics, and Computer Literacy and Availability* by Study Group $(\mathbf{n}=99)$

\begin{tabular}{|c|c|c|}
\hline & $\begin{array}{l}\text { Gabby Group } \\
\quad(\mathrm{n}=50)\end{array}$ & $\begin{array}{l}\text { Control Group } \\
(\mathrm{n}=49)\end{array}$ \\
\hline \multicolumn{3}{|l|}{ Demographics } \\
\hline Age, mean years (SD) & $25.9(3.4)$ & $25.1(3.7)$ \\
\hline \multicolumn{3}{|l|}{ Hispanic, Latino, or Spanish origin } \\
\hline No & $47(94.0)$ & $47(95.9)$ \\
\hline Yes & $3(6.0)$ & $2(4.1)$ \\
\hline \multicolumn{3}{|l|}{ Household income (\$) } \\
\hline$<20,000$ & $3(6.0)$ & $3(6.1)$ \\
\hline $20,000-49,999$ & $13(26.0)$ & $7(14.3)$ \\
\hline$\geq 50,000$ & $15(30.0)$ & $23(46.9)$ \\
\hline Don't know/refused & $19(38.0)$ & $16(32.7)$ \\
\hline \multicolumn{3}{|l|}{ Education } \\
\hline At least some college & $36(72.0)$ & $30(61.2)$ \\
\hline Less than college & $14(28.0)$ & $19(38.8)$ \\
\hline \multicolumn{3}{|l|}{ English as a primary language } \\
\hline No & $5(10.0)$ & $1(2.0)$ \\
\hline Yes & $45(90.0)$ & $48(98.0)$ \\
\hline \multicolumn{3}{|l|}{ Currently a student } \\
\hline No & $30(60.0)$ & $28(57.1)$ \\
\hline Yes & $20(40.0)$ & $21(42.9)$ \\
\hline \multicolumn{3}{|l|}{ Currently employed full time or part time } \\
\hline No & $16(32.0)$ & $12(24.5)$ \\
\hline Yes & $34(68.0)$ & $37(75.5)$ \\
\hline \multicolumn{3}{|l|}{ Clinical characteristics } \\
\hline REALM score, mean $(\mathrm{SD})^{\dagger \neq}$ & $61.5(11.2)$ & $63.0(4.8)$ \\
\hline \multicolumn{3}{|l|}{ REALM-2 category ${ }^{\S}$} \\
\hline High school & $42(91.3)$ & $40(88.9)$ \\
\hline Less than high school & $4(8.7)$ & $5(11.1)$ \\
\hline General Self-Efficacy Scale score, mean (SD) $)^{\|}$ & $33.9(4.7)$ & $33.8(3.8)$ \\
\hline Multidimensional Scale of Perceived Social Support score, mean (SD) ${ }^{\mathrm{qI}}$ & $71.0(9.4)$ & $70.1(9.1)$ \\
\hline 10-Item Everyday Discrimination Scale score, mean $(\mathrm{SD})^{* *}$ & $12.4(8.9)$ & $12.7(6.8)$ \\
\hline \multicolumn{3}{|l|}{ Information technology literacy and access } \\
\hline \multicolumn{3}{|l|}{ Primary location of accessible computer } \\
\hline Home & $27(55.1)$ & $28(57.1)$ \\
\hline Work & $15(30.6)$ & $17(34.7)$ \\
\hline Other & $7(14.3)$ & $4(8.2)$ \\
\hline \multicolumn{3}{|l|}{ Computer experience } \\
\hline I'm an expert & $23(46.0)$ & $28(57.1)$ \\
\hline I use one regularly & $27(54.0)$ & $21(42.9)$ \\
\hline I've never used one & $0(0)$ & $0(0)$ \\
\hline I've tried one a few times & $0(0)$ & $0(0)$ \\
\hline \multicolumn{3}{|l|}{ Computer attitude } \\
\hline I love playing with them & $45(90.0)$ & $42(85.7)$ \\
\hline They're okay & $5(10.0)$ & $7(14.3)$ \\
\hline I don't like them & $0(0)$ & $0(0)$ \\
\hline \multicolumn{3}{|l|}{ Do you ever read about health information online? } \\
\hline No & $3(6.0)$ & $3(6.1)$ \\
\hline Yes & $47(94.0)$ & $46(93.9)$ \\
\hline \multicolumn{3}{|l|}{$\begin{array}{l}\text { Do you ever ask questions or share health information on social networking } \\
\text { sites like Facebook, Twitter, or elsewhere? }\end{array}$} \\
\hline No & $18(36.0)$ & $24(49.0)$ \\
\hline Yes & $32(64.0)$ & $25(51.0)$ \\
\hline
\end{tabular}




\begin{tabular}{lrr}
\hline & $\begin{array}{c}\text { Gabby Group } \\
(\mathrm{n}=50)\end{array}$ & $\begin{array}{c}\text { Control Group } \\
(\mathrm{n}=49)\end{array}$ \\
\hline How frequently do you use the Internet for health information? & & $3(6.0)$ \\
$\quad$ Never & $2(4.0)$ & $1(2.0)$ \\
Rarely & $18(36.0)$ & $17(34.7)$ \\
Sometimes & $9(18.0)$ & $16(32.7)$ \\
Frequently & $18(36.0)$ & $12(24.5)$ \\
Very frequently & & \\
\hline
\end{tabular}

Data are $\mathrm{n}(\%)$ unless otherwise indicated.

*None of the data were statistically significant between the 2 groups at baseline.

${ }^{\dagger}$ Columns do not always add up to number of participants because of missing data.

${ }^{\ddagger}$ The Rapid Estimate of Adult Literacy Levels in Medicine (REALM) is a screening tool designed to measure adults' ability to read common medical words or lay terms that correspond to anatomy or illnesses. It is a 66-item list, with possible scores ranging from 0 to $66 .{ }^{24}$

${ }^{\S}$ REALM scores are dichotomized by high school or more (score of 61 to 66 ) and less than high school (score $\leq 60$ ).

"The General Self-Efficacy Scale is a 10-item psychometric scale designed to assess optimistic self-beliefs related to ability to cope with difficult demands in life. Response options are never (1), sometimes (2), usually (3), or almost always (4), with possible score ranging from 10 to $40 .^{21}$

"IThe Multidimensional Scale of Perceived Social Support scale is a 12-item scale to measure perceived support from family, friends, and significant others. Response options ranged between strongly disagree (1), neutral (4), strongly agree (7) and were summed for a total score. ${ }^{22}$

${ }^{*}$ The Everyday Discrimination Scale is a 10 -item scale to measure the perceived frequency of 10 specific discriminatory experiences. Response options include never (0), less than once a year (1), a few times a year (2), a few times a month (3), at least once a week (4), and almost every day (5), with a possible total score ranging from 0 to $50 .^{23}$

$\mathrm{SD}$, standard deviation.

risks accounted for $29 \%$ of the risks resolved among the Gabby group. On the other hand, there were clinically important risks that were infrequently or never resolved, such as "any current tobacco use" (0 Gabby group participants resolved it of 6 identified at baseline); "currently taking any over-the-counter medicines" (1 of 13 resolved); and "no birth control" (3 of 20 resolved).

Most women in the Gabby group felt that it was easy to talk with Gabby (78\%) and reported that they trusted her (59\%). More than half (56\%) stated that Gabby did a good job of answering their questions, almost two-thirds reported that they had used information from Gabby to improve their health, and another $22 \%$ planned to do so in the future.

\section{Discussion}

The study findings demonstrate that among a group of mostly college-educated, computer literate AA women, the Gabby system can identify preconception risks and initiate actions to reduce the number of preconception risks. Interacting with Gabby was significantly associated with a higher proportion (28\% vs $21 \%$ ) and a greater average number ( 8.3 vs 5.5 ) of $\mathrm{PCH}$ risks being resolved within 6 months compared with women who did not interact with Gabby.
The Gabby system allows women to choose what risks to discuss and when, allowing a woman to avoid talking about risks that might be very important to her health and the health of a future baby (eg, substance use, intimate partner violence), which can lead to shortfalls where a serious risk is identified but discussion and intervention are avoided. However, our previous qualitative work supports providing autonomy and supporting a shared decision-making approach that is more empowering. ${ }^{19}$

The nutrition and physical activity content area contained the most risks triggered, discussed, and resolved. The nutrition section is unique within the Gabby program; it features a curriculum, allowing users to "browse" through a menu of topics. This approach will be applied to other content areas, such as reproductive life planning, in future versions. The system will also feature more culturally tailored content to engage young AA women from a social context. ${ }^{27}$ Current development includes adding 6 narratives that provide background into Gabby's "personal life" and conversational dialog about topics such as hair care, skin care, relationships, and other topics more immediately relevant and applicable to young women's lives.

Our findings regarding participants' trust in Gabby are consistent with other studies that indi- 
cate patients prefer sharing sensitive information with computerized agents whom they perceive to be less judgmental and have more time than traditional providers. ${ }^{28}$ Gabby group participants also reported that it was easy to talk to Gabby, and most indicated that they had already or were planning to use information from Gabby to improve their health. They also were more likely than those in the control group $(64 \%$ vs $51 \% ; P=.21)$ to report at least 1 primary care appointment within 6 months, an important but nonsignificant finding potentially resulting from the relatively short follow-up period.

We believe that women will be asking for interactive health information technology systems, and systems like Gabby will become an important part of health promotion in the future. In its current state the Gabby system is designed for use on a desktop or laptop computer; uptake of the system may have been limited because of the preference of our target population to use a telephone or tablet instead of traditional computer. The average 2.9 logins per user over 6 months fell short of our ideal goal of 1 session per week and underscores the need to plan for the future of Gabby and how women will interact with her outside of the research setting. Mobile devices are an obvious channel, but others, such as integration into clinics and community centers, offer the benefit of weaving Gabby into existing infrastructure, allowing Gabby to immediately connect to services, provide counseling, and initiate referrals. Moreover, multiple channels could be used simultaneously to reach a broader audience.

A limitation of this research is that the follow-up period was relatively short, and behavior change takes time. In addition, data are self-reported, and participants potentially could have misunderstood a question, accidentally selected the wrong response, or intentionally provided misinformation. There could also be social desirability bias when reporting risk status to staff, recall bias affecting baseline and follow-up data, and self-selection bias for study participation. Another limitation that may have led to an underestimation of Gabby's impact is that the control group also received an intervention consisting of a personalized letter listing their identified risks and suggesting that they share this information with their health care provider.

Building on the information gleaned from this RCT, we continue to enhance the Gabby system, and in 2015 we are recruiting nationally for a much larger RCT to include women from a broader range of educational attainment and health literacy over a 12-month period to determine the impact on $\mathrm{PCH}$ risk mitigation. Additional research is planned to determine the impact on clinical outcomes, health care utilization, and ultimately whether Gabby-and even a parallel system for male $\mathrm{PCH}$ - can meaningfully affect some of the racial disparities in reproductive outcomes.

\section{Conclusions}

This version of the Gabby system, with its personally tailored relational and comprehensive approach, holds great promise for improving access to the primary and preventive care assessments women need to prepare for pregnancy. The information gleaned has informed the next version, which is being tested in a much larger RCT. Additional research is also needed to investigate how Gabby can help AA women set their own positive reproductive health agendas, achieve meaningful health behavior changes, and engage in beneficial discourse with their health care provider, partners, and others who provide assistance and support. Gabby can potentially address problems regarding fidelity and cultural sensitivity of message, scale, ease of delivery, and clinician time constraints and can be used across a range of settings, addressing problems identified as barriers to translating PCC best practices to clinical care. ${ }^{29}$

The authors thank Jessica Martin, MA, MPH; Divya Mehta, MPH; Clevanne Julce; Natalie Rock; Stephen Martin, MD, MEd; Huong Tran, MD, MSc; Cathryn Imperato DNP; Justin Alves, RN, ACRN; Juan Fernandez; and Barbara Barry, PhD. The authors also thank the following people and groups for their assistance in carrying out this project: Denisse Ormaza of the Office of Minority Health's PPE program; Kira Watson, PPE President and Liaison for Charles Drew University; Antonia Mead (JSCU site coordinator); La Ronda Jones (CSUN site coordinator); Faye Johnson, Anna Matthews, and Vanessa Jefferson of the Magnolia Project in Jacksonville, Florida; LaRonda Howard of the Teen Health Project of the Northeast Florida Healthy Start Coalition; Janie Tate, South Phoenix Healthy Start; and Judy Ruffin of the Women's Health Branch of the North Carolina Department of Health and Human Services.

\section{References}

1. Atrash H, Jack BW, Johnson K. Preconception care: a 2008 update. Curr Opin Obstet Gynecol 2008;20:581-9.

2. Johnson K, Posner SF, Biermann J, et al; CDC/ ATSDR Preconception Care Work Group; Select 
Panel on Preconception Care. Recommendations for improving preconception health and health careUnited States: a report of the CC/ATSDR preconception care workgroup and the select panel on preconception care. MMWR Recomm Rep. 2006; 55(RR-6):1-23.

3. Jack BW, Culpepper L. Preconception care: risk reduction and health promotion in preparation for pregnancy. JAMA 1990;264:1147-9.

4. Jack BW, Atrash H, Coonrod DV, Moos MK, O'Donnell J, Johnson K. The clinical content of preconception care: an overview and preparation of this supplement. Am J Obstet Gynecol 2008; 199(Suppl):S266-79.

5. Atrash H, Jack BW, Johnson K, et al. Where is the "W"oman in MCH? Am J Obstet Gynecol 2008; 199(Suppl):S259-65.

6. Floyd RL, Johnson KA, Owens JR, Verbiest S, Moore CA, Boyle C. A National action plan for promoting preconception health and health care in the United States (2012-2014). J Womens Health (Larchmt) 2013;2210:797-802.

7. Henderson JT, Weisman CS, Grason H. Are two doctors better than one? Women's physician use and appropriate care. Womens Health Issues 2002;12:138-49.

8. Bickmore T, Gruber A, Picard R. Establishing the computer-patient working alliance in automated health behavior change interventions. Patient Educ Couns 2005;59:21-30.

9. Bickmore T, Giorgino T. Health dialog systems for patients and consumers. J Biomed Inform 2006;39: 556-71.

10. Bickmore T, Puskar K, Schlenk E, Pfeifer L, Sereika S. Maintaining reality: relational agents for antipsychotic medication adherence. Interact Comput 2010; 22:276-88.

11. King A, Bickmore T, Campero M, et al. Employing "virtual advisors" in preventive care for underserved communities: results from the COMPASS study. J Health Commun 2013;18:1449-64.

12. Bickmore TW, Pfeifer LM, Byron D, et al. Usability of conversational agents by patients with inadequate health literacy: evidence from two clinical trials. J Health Commun 2010;15(Suppl 2):197-210.

13. Kutner M, Greenberg E, Jin Y, Paulsen C. The health literacy of America's adults: results from the 2003 National Assessment of Adult Literacy (NCES 2006-483). Washington, DC: National Center for Education Statistics, US Department of Education; 2006.

14. Johnson RL, Roter D, Powe NR, Cooper LA. Patient race/ethnicity and patient-physician communication during medical visits. Am J Public Health 2004;94:2084-90.

15. Yarnell KS, Pollak KI, Østbye T, Krause KM, Michener JL. Primary care: is there enough time for prevention? Am J Public Health 2003:93;635-41.
16. Shires DA, Stange KC, Divine G, et al. Prioritization of evidence-based preventive health services during periodic health examinations. Am J Prev Med 2012;42:164-73.

17. Ellis T, Latham N, DeAngelis T, Thomas C, SaintHilaire M, Bickmore T. Feasibility of a virtual exercise coach to promote walking in community-dwelling persons with Parkinson disease. Am J Phys Med Rehabil 2013;92:472-85.

18. Bickmore T, Silliman R, Nelson K, et al. Randomized controlled trial of an automated exercise coach for older adults. J Am Geriatr Soc 2013;61:1676-83.

19. Gardiner P, Hempstead M, Ring L, et al. Reaching women through health information technology: the gabby preconception care system. Am J Health Promot 2013;27(3 Suppl):eS11-20.

20. Office of Minority Health. Preconception peer educators program. September 24, 2013. Washington, DC: US Department of Health and Human Services. Available from http://minorityhealth.hhs.gov/ omh/browse.aspx?lvl=3\&lvlid=9. Accessed August $13,2014$.

21. Schwarzer R, Jerusalem M. Generalized Self-Efficacy scale. In: Weinman J, Wright S, Johnston M, eds. Measures in health psychology: a user's portfolio. Causal and control beliefs. Windsor, UK: NFER-NELSON; 1995:35-37.

22. Bruwer B, Emsley R, Kidd M, Lochner C, Seedat S. Psychometric properties of the Multidimensional Scale of Perceived Social Support in youth. Compr Psychiat 2008;49:195-201.

23. Lewis TT, Yang FM, Jacobs EA, Fitchett G. Racial/ ethnic differences in responses to the Everyday Discrimination Scale: a differential item functioning analysis. Am J Epidemiol 2012;175:391-401.

24. Davis TC, Crouch MA, Long SW, et al. Rapid assessment of literacy levels of adult primary care patients. Fam Med 1991;23:433-5.

25. Kroenke K, Spitzer RL, Williams JB. The Patient Health Questionnaire-2: validity of a two-item depression screener. Med Care 2003;41:1284-92.

26. Cohen S, Kamarck T, Mermelstein R. A global measure of perceived stress. J Health Soc Behav 1983; 24:385-96.

27. Kreuter M, Wray R. Tailored and targeted health communication: strategies for enhancing information relevance. Am J Health Behav 2003;27:S227-32.

28. Bickmore T, Pfeifer L, Jack BW. Taking the time to care: empowering low health literacy hospital patients with virtual nurse agents. Proceedings of the ACM SIGCHI Conference on Human Factors in Computing Systems (CHI), April 4-9, 2009, Boston, MA.

29. Jack B, Atrash A, Bickmore T, Johnson K. The future of preconception care. Womens Health Issues 2008;18(Suppl):S19-25. 


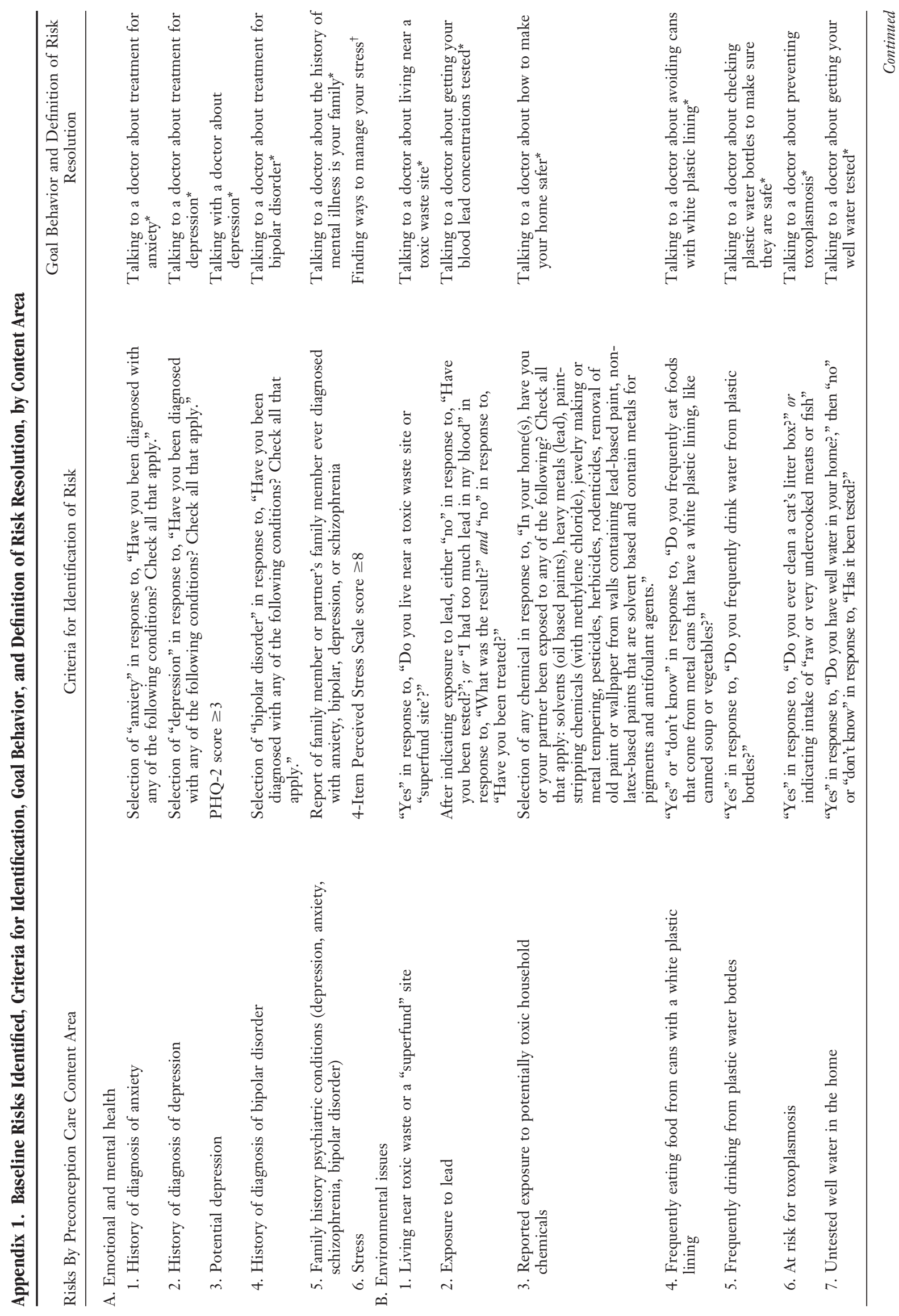




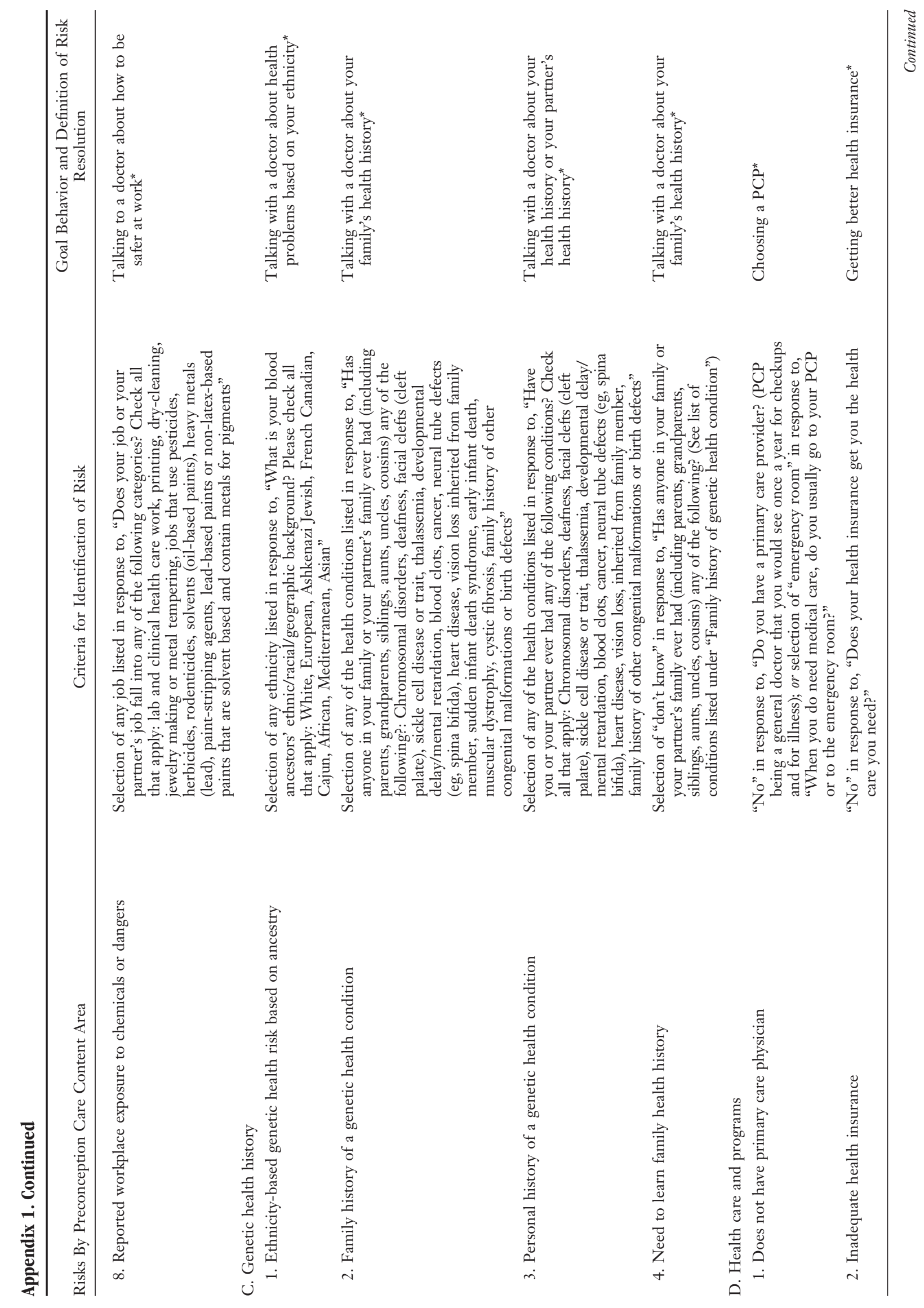




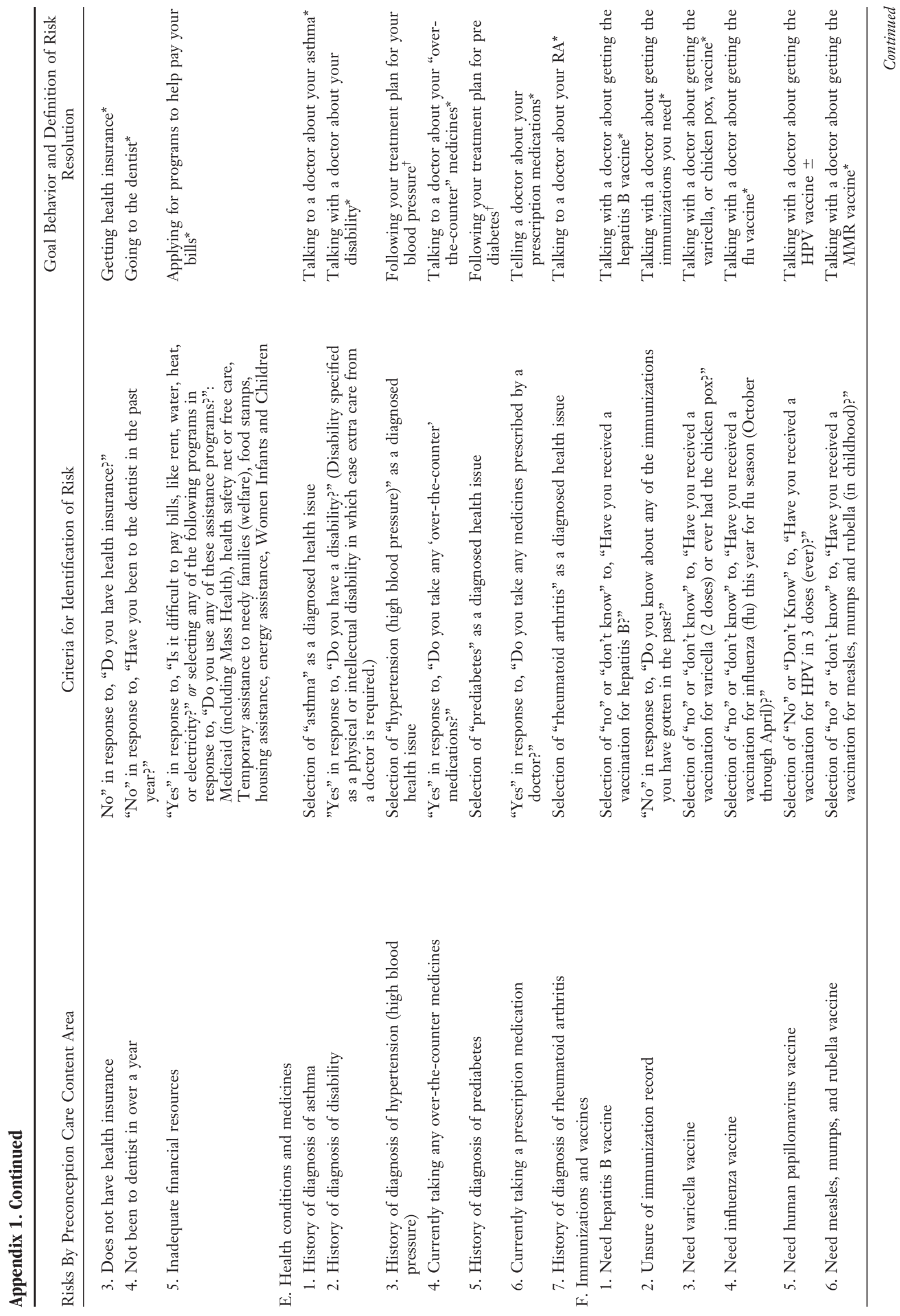




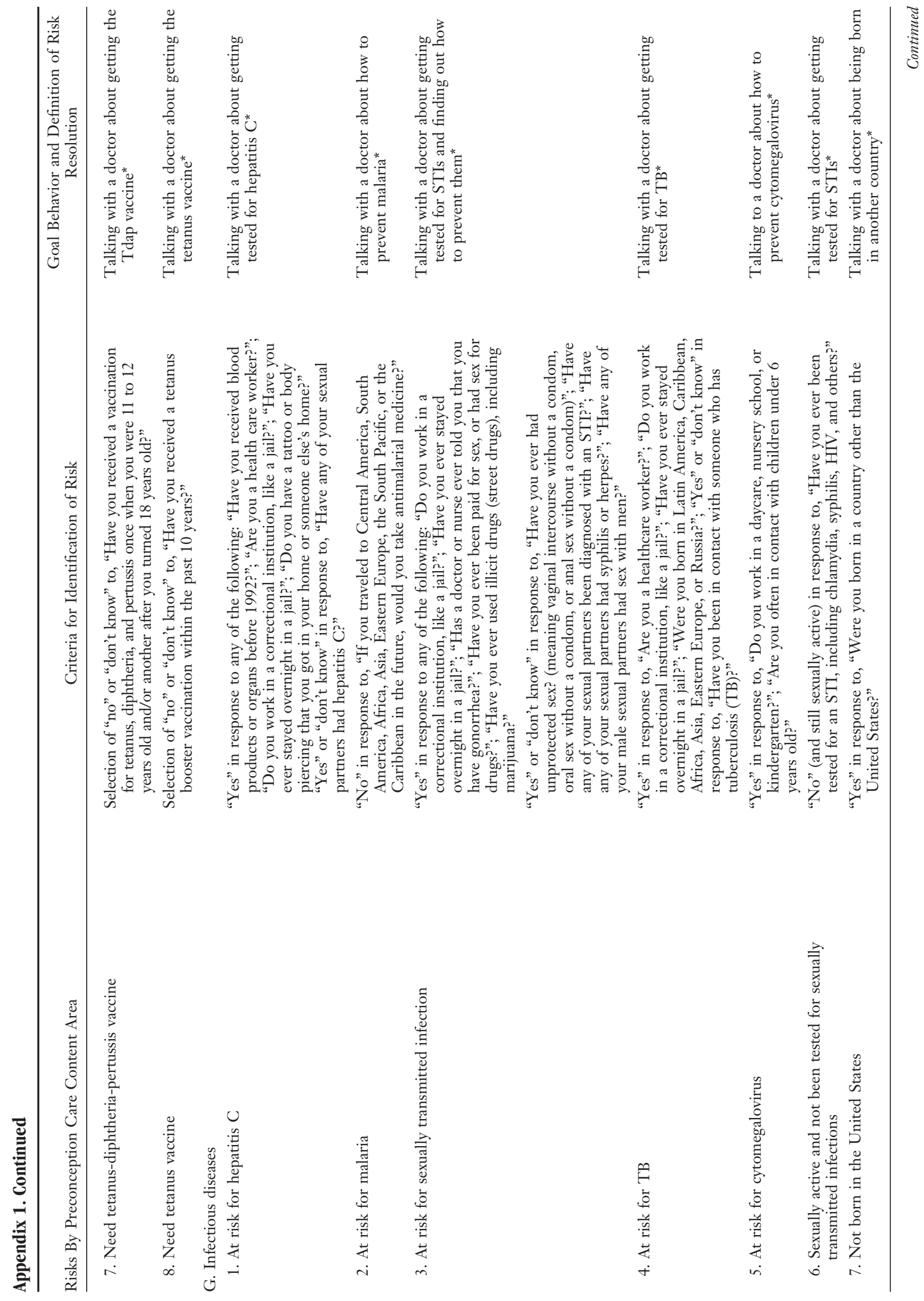

E4 JABFM July-August 2015 Vol. 28 No. 4 


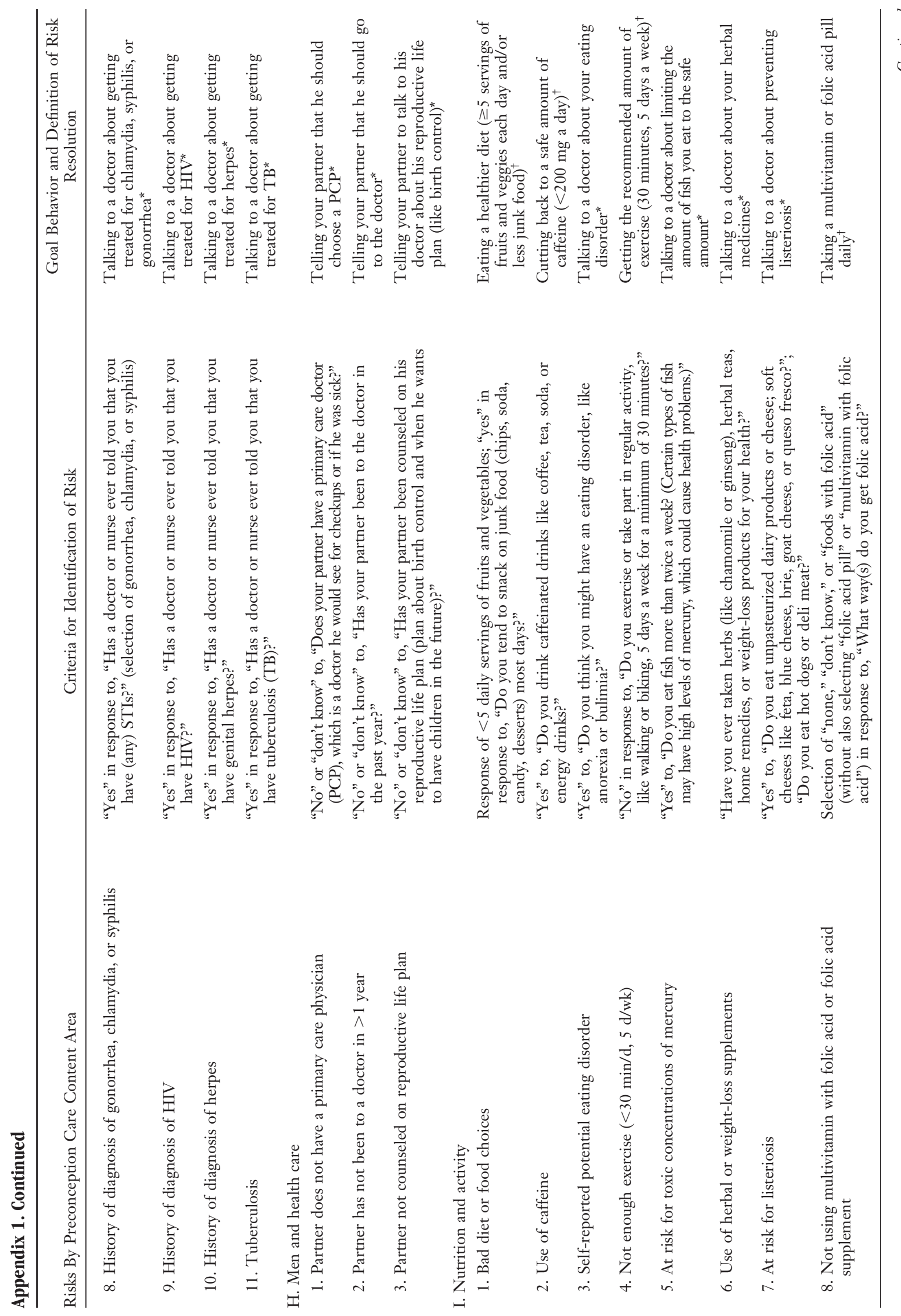




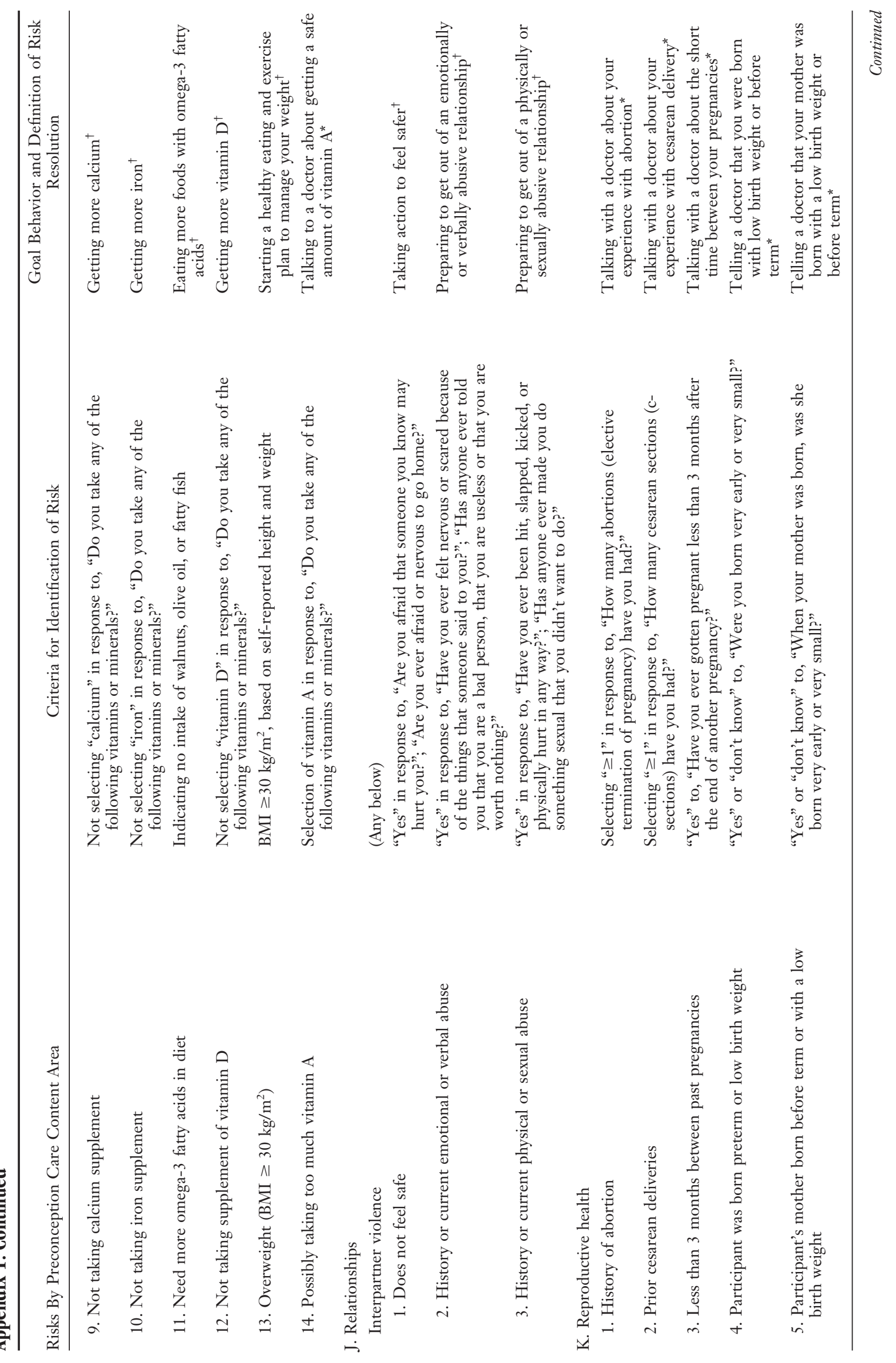




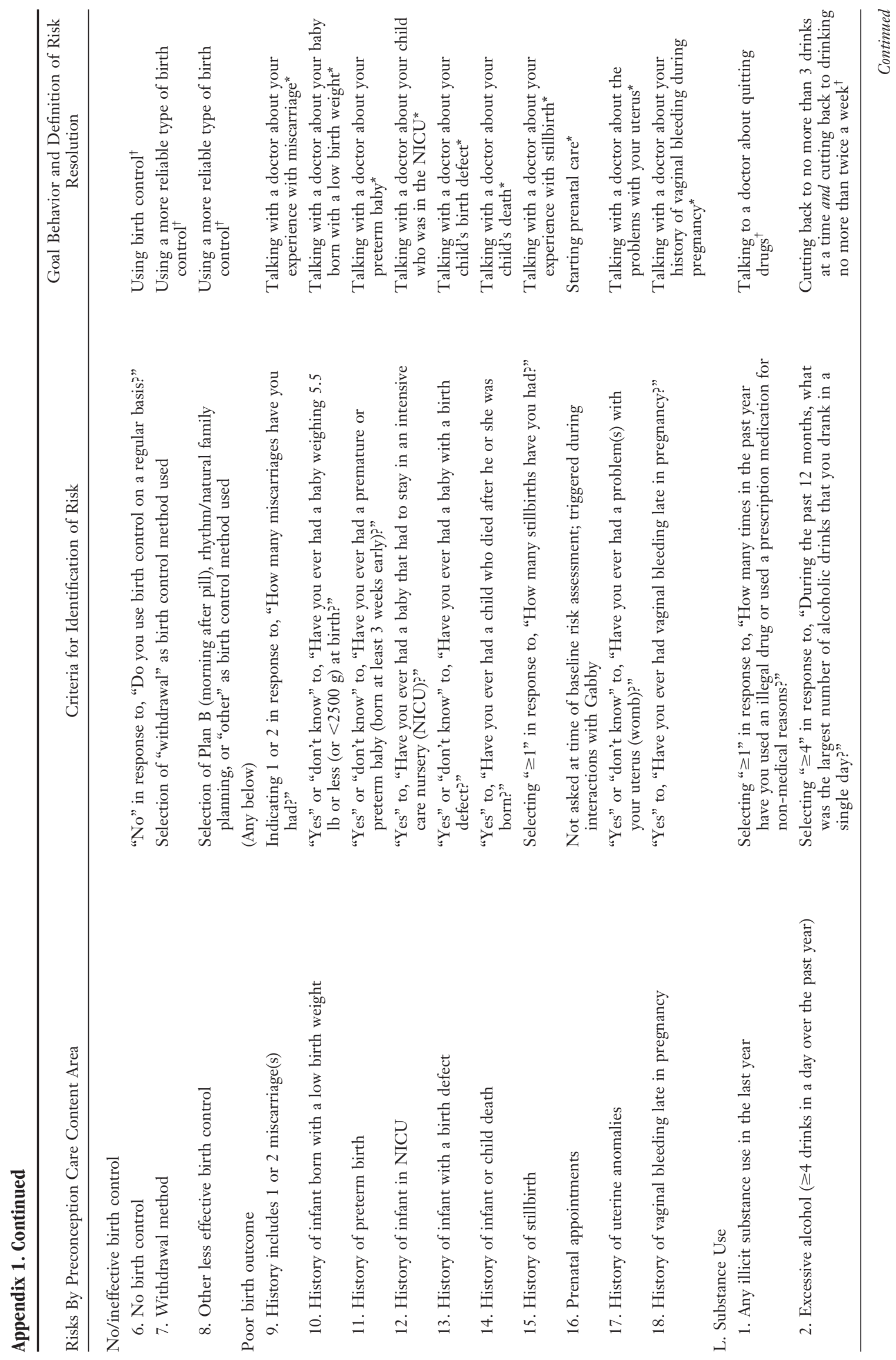




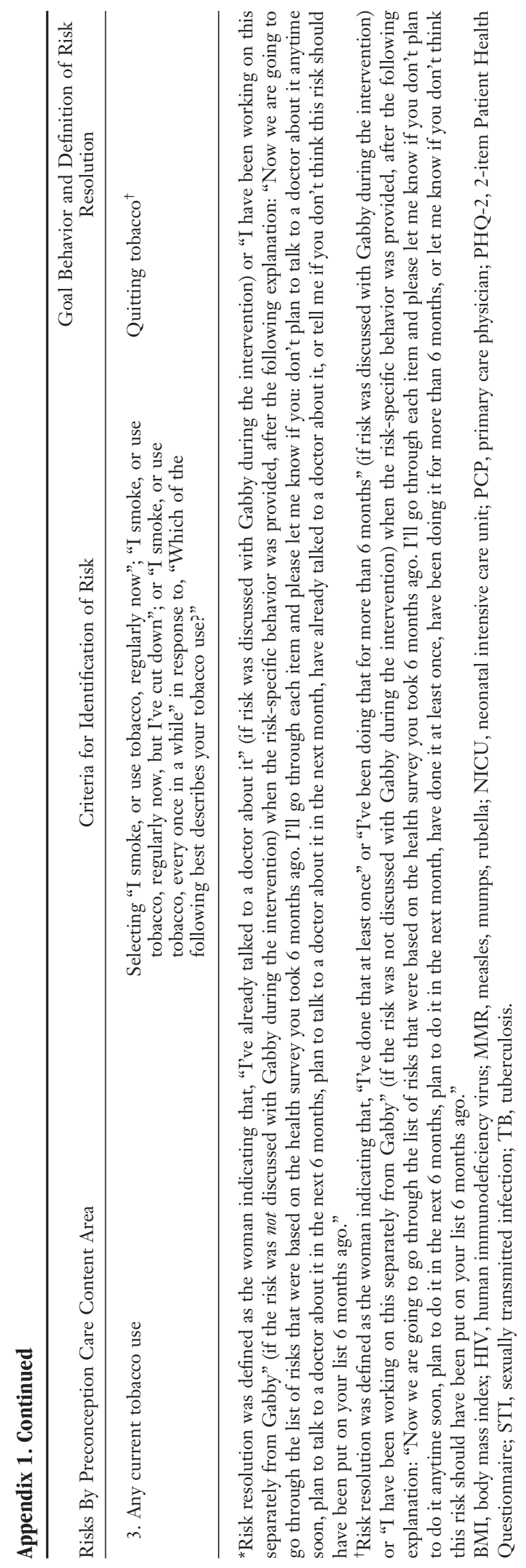

E8 JABFM July-August 2015 Vol. 28 No. 4 


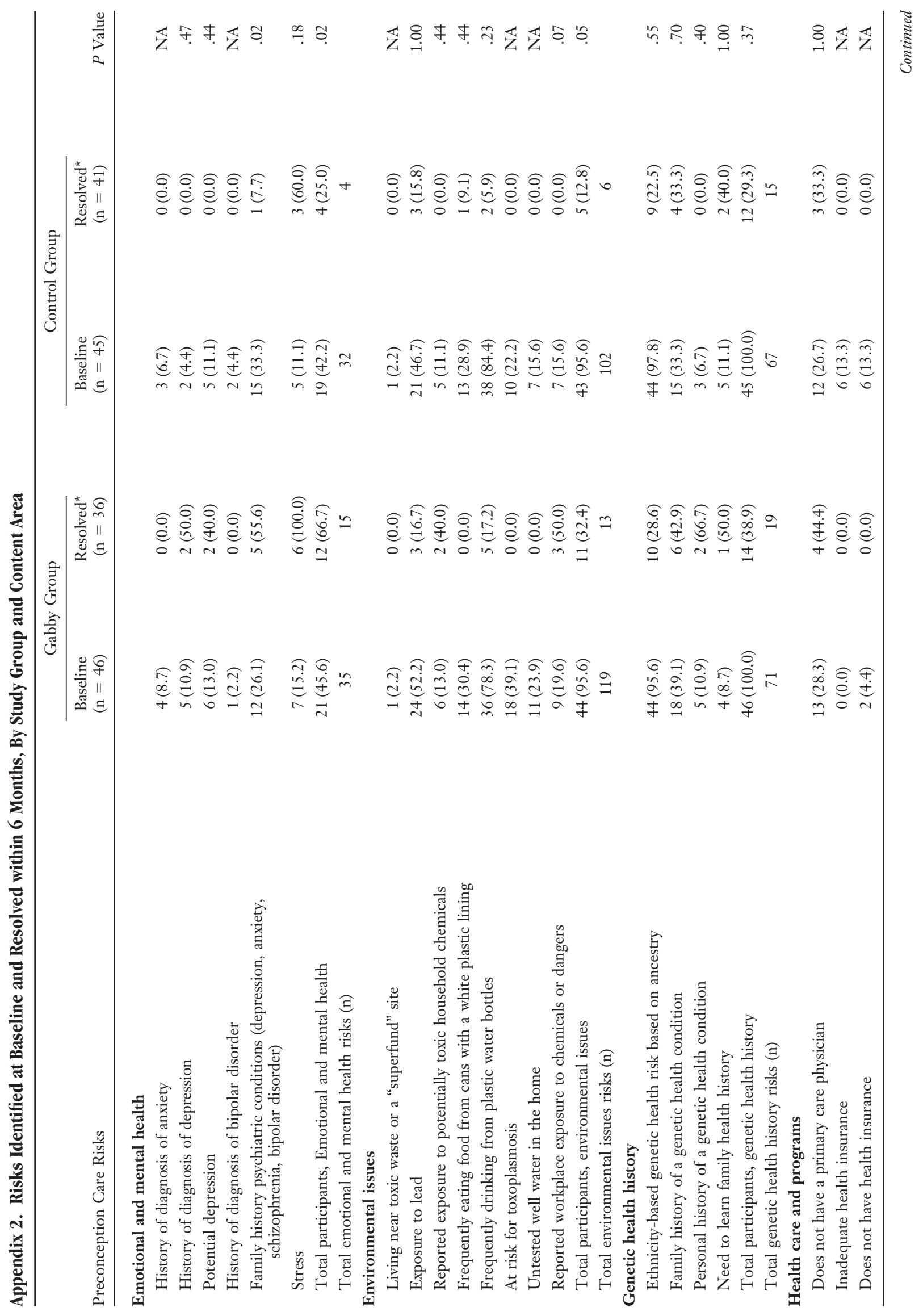




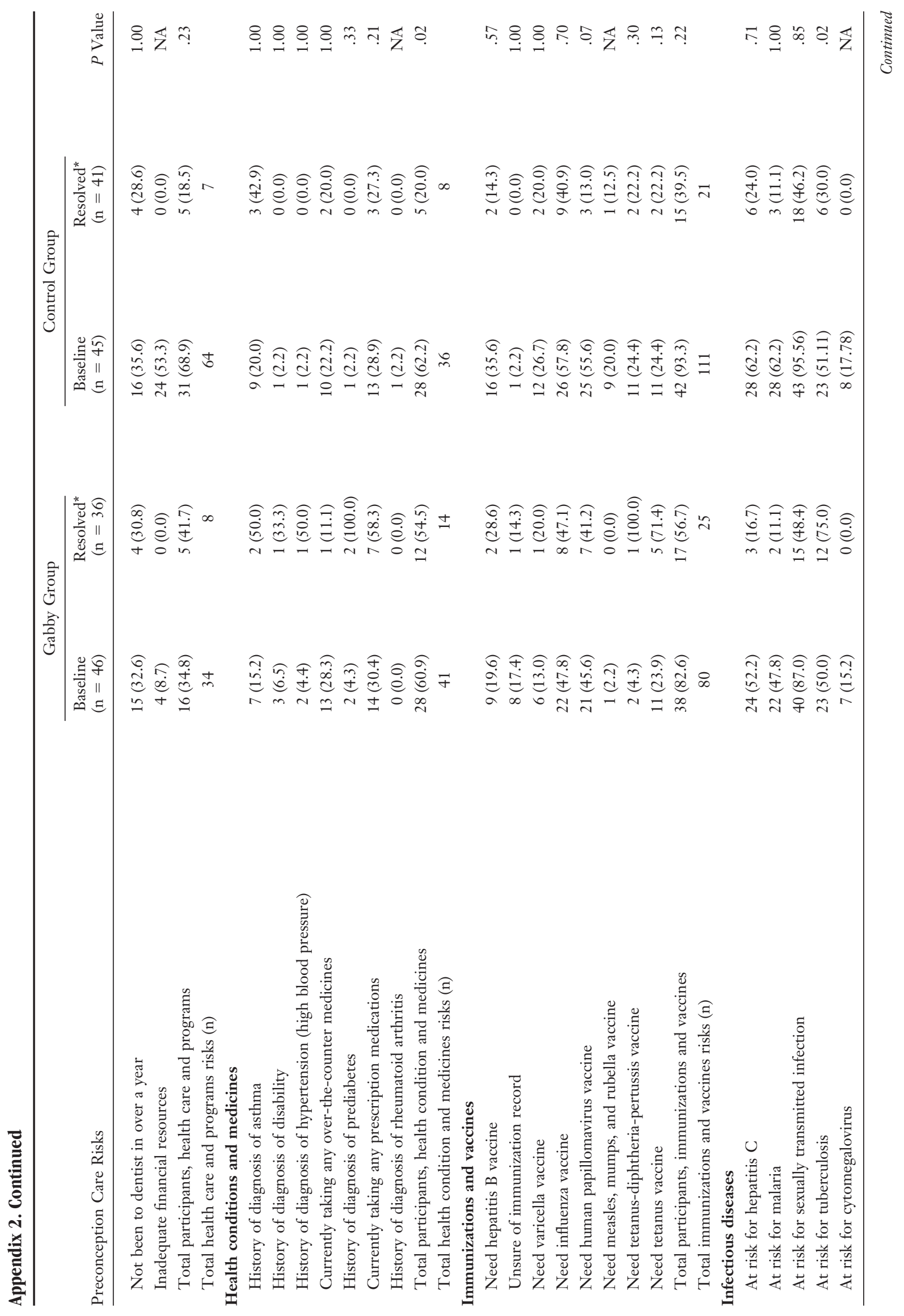




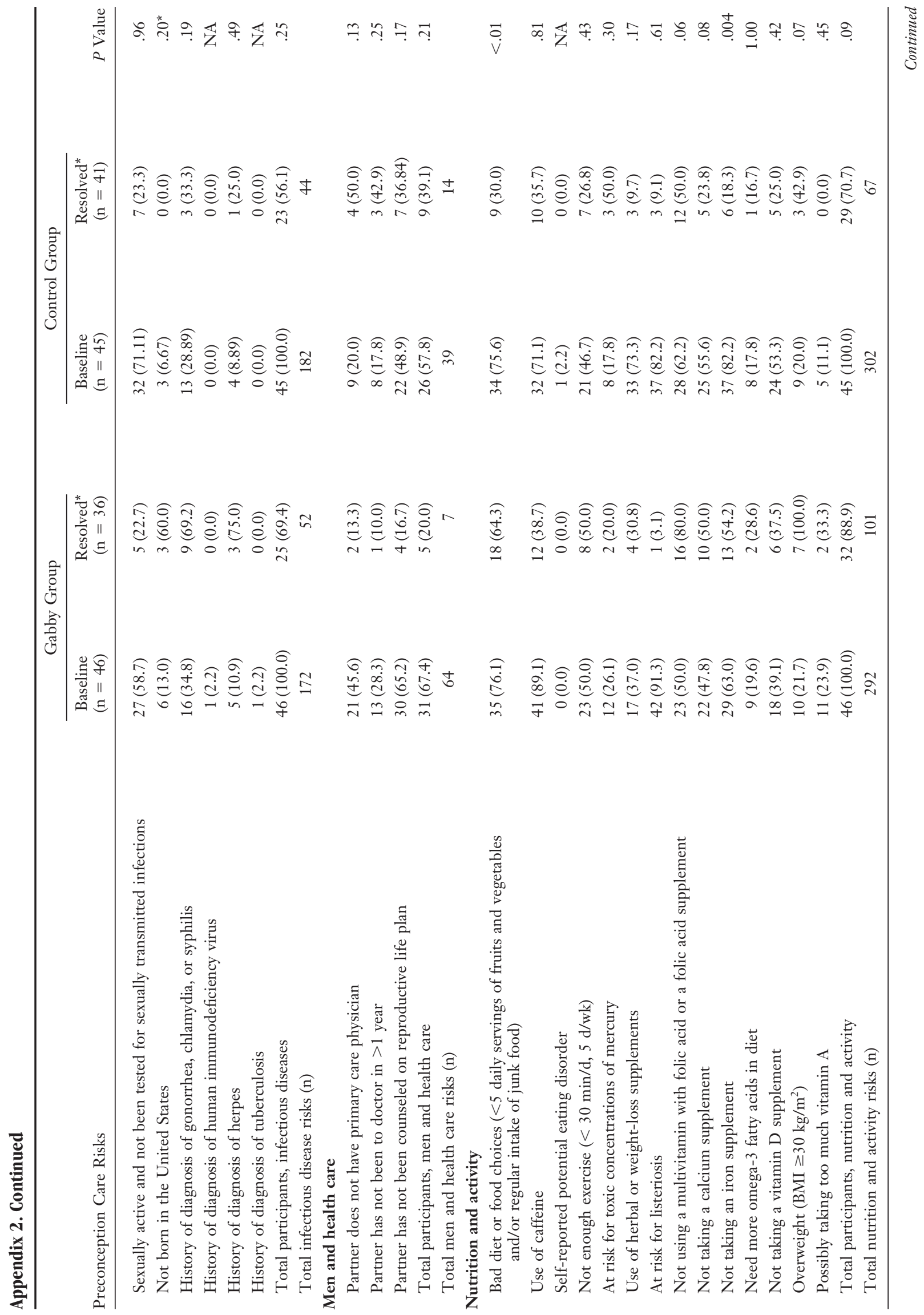




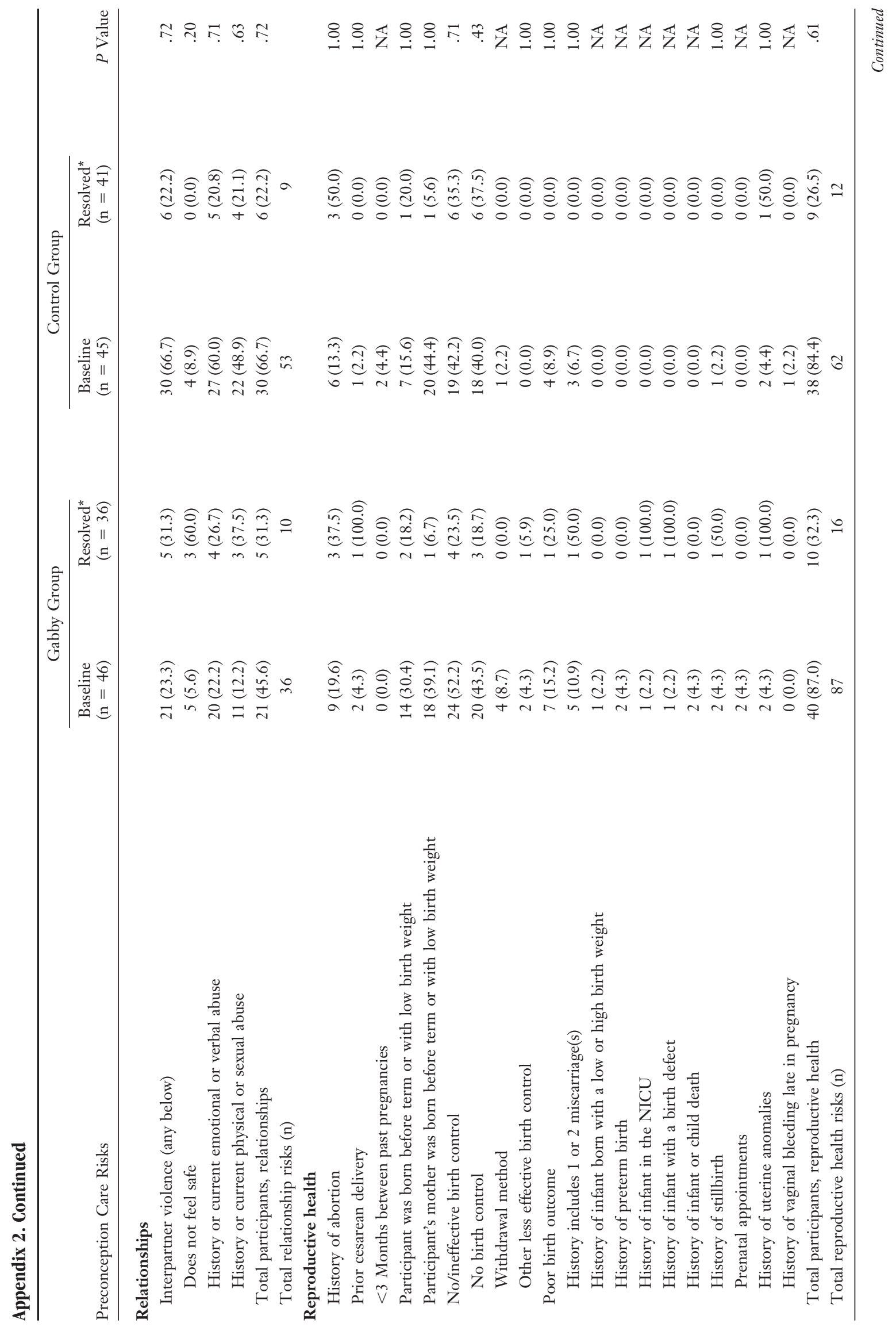




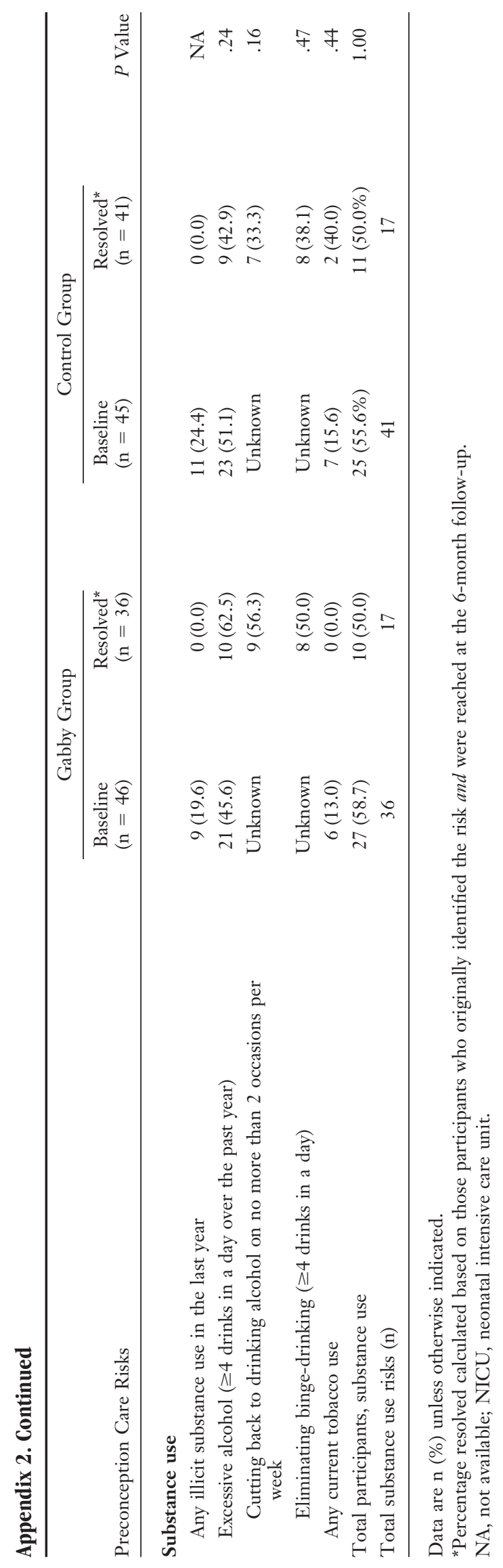

